Foy, H. \& Kondi, A. (I 960 ). Trans. R. Soc. trop. Med. Hyg. 54, 419.

Gerritsen, R., Walker, A. R. P., de Meillon, B. \& Yeo, R. M. (I953). Trans. R. Soc. trop. Med. Hyg. 47,134 .

Gilles, H. M. (1957). Ann. trop. Med. Parasit. 51, 58.

Indian Council of Medical Research. (I951). Spec. Rep. Ser. Indian Coun. med. Res. no. 20.

Jung, R. C. \& Beaver, P. C. (r95 I). Pediatrics, Springfield, 8, 548 .

Linley-Adams, J. C. (1953). Brit. med. F. i, 8 I9.

McGregor, I. A., Gilles, H. M., Walters, J. H., Davies, A. H. \& Pearson, F. A. (1956). Brit. med. J. ii, 686 .

McGregor, I. A. \& Smith, D. A. (1952). Trans. R. Soc. trop. Med. Hyg. 46, 403 .

Nyberg, W. (1963). Proc. Nutr. Soc. 22, 8.

Platt, B. S. (1957). Amer. F. trop. Med. Hyg. 6, 773.

Roche, M. (1956). Lancet, 270, 965 .

Roche, M., Perez-Gimenez, M. E., Layrisse, M. \& Prisco, E. D. (1957). \%. clin. Invest. 36, I 183.

Seddik, Y. (1950). Effect of various dietary proteins on the rat before and after infestation with Nippostrongylus muris. Ph.D. Thesis, University of London.

Shearer, G. D. \& Stewart, J. (1932-3). Rep. Inst. Anim. Path. Univ. Camb. p. 77.

Stewart, J. (1932-3). Rep. Inst. Anim. Path. Univ. Camb. p. $5^{8 .}$

Stott, G. (196r). Trans. R. Soc. trop. Med. Hyg. 55, 20.

'Tasker, P. W. G. (1961). Trans. R. Soc. trop. Med. Hyg. 55, 36.

Trowell, H. C. (1949). Trans. R. Soc. trop. Med. Hyg. 42, 4r7.

Trowell, H. C. \& Vaizey, M. (1956). Lancet, 27I, I28I.

Venkatachalam, P. S. \& Patwardhan, V. N. (1953). Trans. R. Soc. trop. Med. Hyg. 47, 169.

Walker, A. R. P. (I 956). Trans. R. Soc. trop. Med. Hyg. 50, 509.

Walker, A. R. P. \& de Lacy, C. (I962). Trans. R. Soc. trop. Med. Hyg. 56, 173.

\title{
Diphyllobothrium latum and human nutrition, with particular reference to vitamin $B_{12}$ deficiency
}

\section{By Wolmar Nyberg, Laboratory Department, Vasa Central Hospital, Vasa, Finland}

The effect of intestinal helminths on their hosts has been widely studied, and the importance of relating these effects to the nutrition of the host is evident. As regards Diphyllobothrium latum, the only relatively well-known aspect of its nutritional influence is the vitamin $B_{12}$ deficiency it causes in its host. Therefore, I shall expand mostly on this theme. During recent years the possibility of disturbances in the utilization of other vitamins has also been subjected to preliminary investigations. Further, knowledge has accumulated regarding the symptomatology of fish-tapeworm infection, which may also have nutritional implications.

\section{Vitamin $B_{12}$ deficiency and fish-tapeworm infection}

The views of our group regarding what happens in an intestine containing D. latum are diagrammatically represented in Fig. I. Normally, a considerable proportion of the vitamin $B_{12}$ ingested in the food is absorbed. In the presence of worm infection there is competition between the parasite and the host for the vitamin $B_{12}$ available. In this situation the worm almost always utilizes most of the vitamin, leaving inadequate amounts to be absorbed by the host. The consequence is a gradually developing vitamin $\mathrm{B}_{12}$ depletion with a vitamin $\mathrm{B}_{12}$ deficiency state as the final result. This state manifests itself as the well-known disease called pernicious anaemia. The investigations that have led to this conclusion have been extensively 


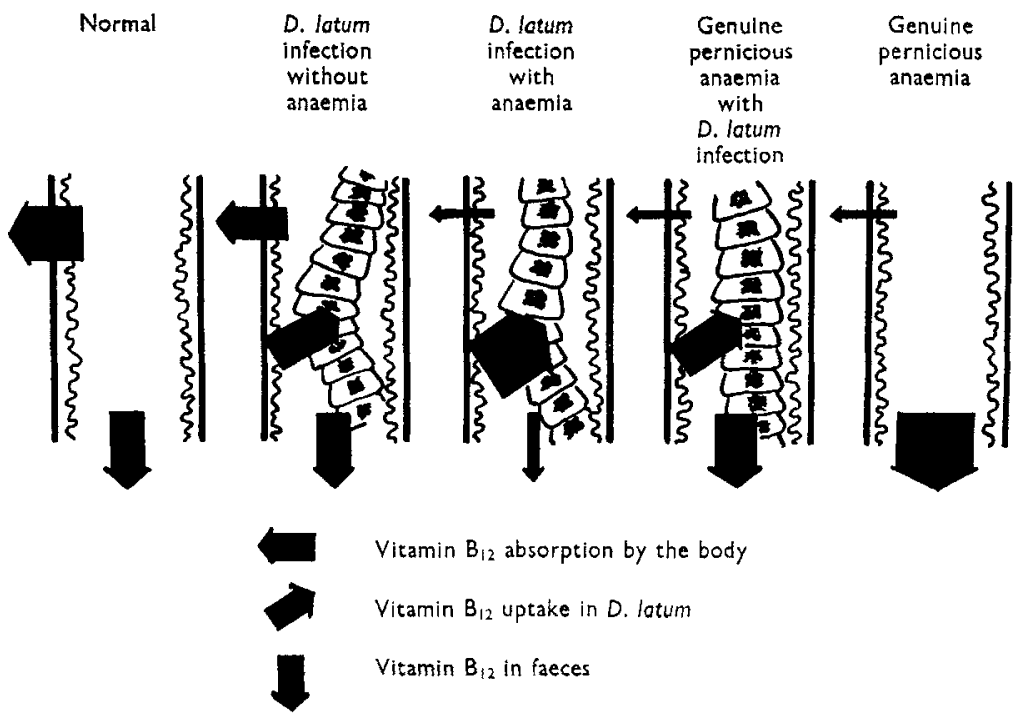

Fig. I. A schematic picture of the relative amounts of vitamin $B_{12}$ absorbed from the intestine in healthy persons, subjects infected with Diphyllobothrium latum, and patients suffering from genuine pernicious anaemia with and without tapeworm infection.

reviewed by my former chief, von Bonsdorff (1956, I958). However, a short summary is presented: ( $\mathrm{r}$ ) Dried tapeworm can be used as a substitute for vitamin $\mathrm{B}_{12}$ (von Bonsdorff \& Gordin, 1952). (2) Genuine pernicious anaemia can be cured with extracts of fish tapeworm (von Bonsdorff \& Gordin, 1953). (3) D. latum contains a very high vitamin $B_{12}$ activity as measured microbiologically, ranging from $1 \cdot 3$ to $3.0 \mu \mathrm{g} / \mathrm{g}$ dry worm (Nyberg, 1952). (4) The parasite has a high uptake of radioactive vitamin $B_{12}$ when this vitamin is given orally to patients harbouring the worm (Nyberg, 1958): (5) The absorption of radioactive vitamin $B_{12}$ by the host is significantly lower in tapeworm carriers than in non-infected persons, which is true both for anaemic and non-anaemic subjects (Nyberg, Gräsbeck \& Sippola, 1958). (6) All subjects with fish-tapeworm anaemia whose serum vitamin $B_{12}$ concentrations have been studied have shown pathologically low values, below I00 $\mu \mu \mathrm{g} / \mathrm{ml}$ serum (values for about seventy subjects collected from the literature). (7) Non-anaemic D. latum carriers have significantly lower vitamin $\mathrm{B}_{12}$ concentrations in their blood than non-carriers. In addition, a little over $50 \%$ of the worm carriers without anaemia have pathologically low serum vitamin $B_{12}$ levels (Nyberg, Gräsbeck, Saarni \& von Bonsdorff, I96r).

Two important facts must be stressed: (I) The majority of non-anaemic worm carriers have a defective vitamin $B_{12}$ absorption. (2) More often than not, the worm has a harmful effect on the vitamin $B_{12}$ metabolism of its host. We should therefore not distinguish very sharply between tapeworm carriers with anaemia and those without anaemia. The reason that a fully developed vitamin $B_{12}$ deficiency state, i.e. pernicious anaemia, is not always seen, is explained by the fact that the stores of vitamin $B_{12}$ in the organism are considerable, and the turnover rate of the vitamin is slow (Gräsbeck, ig60). 
The amount of vitamin $B_{12}$ in the worm is remarkably constant. We therefore imagine that the worm always takes whatever it needs of the vitamin $B_{12}$ available in the ingested food of its host. The demands for vitamin $B_{12}$ may, however, vary both in the worm and the host. The biochemical systems in the worm which require such huge amounts of vitamin $B_{12}$ are not fully understood. We know, however, that vitamin $\mathrm{B}_{12}$ is essential for the synthesis of deoxyribonucleic acids. It is therefore possible that the requirement of the worm for vitamin $B_{12}$ may be related to its rapid growth and huge production of eggs. If this view is correct, every factor which influences the growth and the egg production may also change the demand of the parasite for vitamin $B_{12}$, which in turn will alter the vitamin $B_{12}$ absorption of the host. Further, in conditions when the need of the host for the vitamin is unusually high (pregnancy, febrile states, hyperthyroidism) there is a greater possibility of a negative vitamin $B_{12}$ balance in the host when the worm is present. Other factors, too, may have an effect on the vitamin $B_{12}$ absorption of the host. Thus it is evident from our investigations that the vitamin $B_{12}$ absorption of the host is especially inadequate when food contains inadequate amounts of vitamin $B_{12}$, when the worm is very large, and when the worm is situated in the upper parts of the gut where it is in contact with the food at an early stage of the digestive process (von Bonsdorff, 1958).

This last point has recently been criticized by Villako ( 1961 ), who states that the position of the worm in the intestine is of no importance in the development of the tapeworm anaemia. Villako also reports that $D$. latum contains antibacterial substances which change the intestinal flora in such a way that the absorption of vitamin $\mathrm{B}_{12}$ and other vitamins is disturbed, but $I$ have not managed to find the original data supporting this statement. However, it is difficult to imagine that, other conditions being equal, the absorption of vitamin $\mathrm{B}_{12}$ of a person would be the same regardless of whether the worm was situated in the duodenum or in the lower end of the ileum.

Taking everything into account, we may think that the absorption of vitamin $B_{12}$ will vary from time to time, depending on the actual situation in the intestine where the competition between the worm and the host takes place. Thus a long period of poor absorption may be followed by a period of satisfactory absorption, after a vitamin $B_{12}$-rich meal for instance, which for the moment, may prevent the development of a manifest vitamin $B_{12}$ deficiency.

The normal human stomach secretes a substance of somewhat obscure nature, probably a protein, called Castle's intrinsic factor, which is essential for the absorption of vitamin $B_{12}$. As shown by my countryman and collaborator Gräsbeck, and workers in other parts of the world (Gräsbeck, I960), this intrinsic factor combines with vitamin $B_{12}$ to form a very stable complex. If intrinsic factor is lacking in the gastric juice, as in genuine pernicious anaemia, vitamin $B_{12}$ is not absorbed. In tapeworm infection, with or without anaemia, the vitamin $B_{12}$ deficiency must be due to factors other than those operating in Addison's anaemia, because the majority of worm carriers have intrinsic factor in their gastric juices. 
It has long been postulated that the worm interferes with the interaction between the intrinsic factor and vitamin $\mathrm{B}_{12}$. This was quite evident already from the earlier work of von Bonsdorff before vitamin $\mathrm{B}_{12}$ was known. (For details see von Bonsdorff, 1958.) The way in which the fish tapeworm acts on the intrinsic factor or on the intrinsic factor-vitamin $\mathrm{B}_{12}$ complex has not been known until recently. Using radioactive vitamin $\mathrm{B}_{12}$ as an indicator I managed to show (Nyberg, $1960 b$ ) that the worm contains a principle capable of splitting off vitamin $B_{12}$ from its intrinsic factor-bound form. We have named this as yet chemically uncharacterized substance 'releasing factor'. It can be extracted from the worm with ethanol and chloroform, and further purified chromatographically with the aid of DEAE-Sephadex columns. When such tapeworm extracts are incubated with vitamin $B_{12}$ bound by gastric juice, more than $90 \%$ of the vitamin can be released, as seen from Table $\mathrm{I}$. The

Table I. Effect of extracts made from five tapeworms on complex-bound vitamin $B_{12}$ (Nyberg, unpublished)

(0.02 $\mu \mathrm{g}{ }^{60} \mathrm{Co}$-labelled vitamin $\mathrm{B}_{12}$ bound per $\mathrm{ml}$ neutral, depepsinized human gastric juice; I $\mathrm{ml}$ samples incubated with $3 \mathrm{ml}$ worm extract and then dialysed. Control samples contained only bound vitamin $B_{12}$ or free vitamin $B_{12}$ )

\begin{tabular}{lccccc}
\multicolumn{5}{c}{$\begin{array}{c}\text { Decrease in radioactivity } \\
\text { Matter incubation and dialysis (\%) }\end{array}$} \\
Bound vitamin $\mathrm{B}_{12}+$ worm extract & 57 & 88 & 72 & 4 & 5 \\
Bound vitamin $\mathrm{B}_{12}$ only & $\mathrm{r}$ & 2 & 3 & 93 & 69 \\
Vitamin $\mathrm{B}_{12}$ only & 0 & 0 & 0 & 0 & 0 \\
& 100 & 98 & 97 & 100 & 100
\end{tabular}

worm can release vitamin $\mathrm{B}_{12}$ bound to other proteins, also. This property was demonstrated for rat liver, intestine, kidney and muscle into which radioactive vitamin $B_{12}$ had been incorporated in vivo (Nyberg, unpublished). The ability of the worm to release vitamin $B_{12}$ from its bound form also in vivo has been shown indirectly in clinical experiments (Nyberg, r960a).

It seems logical to assume that the releasing of vitamin $B_{12}$ is the first step in the mechanism used by the worm to assimilate it. It may also be a key to further elucidation of the details of the incorporation of vitamin $B_{12}$ in the worm.

\section{Symptomatology of fish tapeworm infection}

The symptoms caused by a parasite reflect the effect exerted by this organism on its host, and may thus have nutritional implications. The fish-tapeworm anaemia has been known for about 70 years, and it has been thoroughly studied during this period. However, very little attention has been given to the possible deleterious effect of $D$. latum on non-anaemic worm carriers. Earlier investigations regarding the symptoms caused by the worm are mainly based on hospital patients. Symptoms caused by the tapeworm anaemia and those originating from other diseases have to a large extent been confused with clinical signs produced by the worm itself. Also the general concept of the harmful effect of the worm on its human host has 
been greatly influenced by the popular interpretation of the consequences of a worm infection. For instance, the idea that the worm has such a voracious appetite that the host loses weight is quite common. Considering the size of this unusually big intestinal helminth it is understandable that laymen, aware of a tapeworm infection, focus their feelings of indisposition on the abdominal area. In regions in Finland where there is heavy infestation the majority of the worm carriers state that they have no symptoms due to the parasite. The only thing that troubles them is that 'there may be too much of the worm'. Most investigators interested in the subject are also of the opinion that the majority of worm carriers enjoy perfect general health (Birkeland, r932).

In an attempt to clear up the confusion about the symptomatology of $D$. latum infection our group made a large field study in the eastern parts of Finland where I 345 persons were investigated. During this mass examination every subject had to fill in a questionnaire form regarding his symptoms. At the same time blood and faeces samples were taken for later investigations. Details of this survey are reported elsewhere (Saarni, Nyberg, Gräsbeck \& von Bonsdorff, 1962). As there were no facilities to perform nutritional and metabolic balance studies, we had to rely on information obtained from the history in evaluating the effects of the worm on its human host. However, as the investigations included persons fully fit for work and a large control series, and also a thorough statistical analysis with the aid of an electronic computer, we are convinced that this study gives a more realistic picture of the symptoms caused by the fish tapeworm than earlier investigations.

Table 2. Incidence of symptoms in 295 non-anaemic tapeworm carriers and in 832 control subjects

(From Saarni et al. 1962)

Symptom
Not perfectly healthy
Craving for salt
Diarthoea
Fatigue and weakness
Dizziness
Numbness of the extremities
Sensation of hunger
Reduced sensibility
Headache
Impaired night vision
Sore tongue
Abdominal pains
Heartburn
Formication
Sore gums
Troubles resulting from incoordination
and disturbed motility
Meteorism
Soreness of the corners of the mouth
Constipation
Loss of weight

$\begin{array}{rc}\text { No. } & \% \\ 174 & 59 \cdot 0 \\ 183 & 62 \cdot 0 \\ 65 & 22 \cdot 0 \\ 194 & 65 \cdot 8 \\ 156 & 52 \cdot 9 \\ 145 & 49 \cdot 2 \\ 109 & 36 \cdot 9 \\ 24 & 8 \cdot 1 \\ 126 & 42 \cdot 7 \\ 158 & 53 \cdot 6 \\ 51 & 17 \cdot 3 \\ 133 & 45 \cdot 1 \\ 96 & 32 \cdot 5 \\ 41 & 13 \cdot 9 \\ 38 & 12 \cdot 9 \\ & \\ 32 & 10 \cdot 8 \\ 113 & 38 \cdot 3 \\ 38 & 12 \cdot 9 \\ 77 & 26 \cdot 1 \\ 18 & 6 \cdot 1\end{array}$

\begin{tabular}{|c|c|}
\hline Contr & abjects \\
\hline No. & $\%$ \\
\hline 363 & $43 \cdot 6$ \\
\hline 346 & $4 I \cdot 6$ \\
\hline & $9 \cdot 9$ \\
\hline 413 & $49 \cdot 6$ \\
\hline 321 & $38 \cdot 6$ \\
\hline 311 & $37 \cdot 4$ \\
\hline 226 & $27 \cdot 2$ \\
\hline 34 & $4 \cdot I$ \\
\hline 286 & $34 \cdot 4$ \\
\hline 388 & $46 \cdot 6$ \\
\hline 105 & I 2.6 \\
\hline $33 \mathrm{I}$ & $39 \cdot 8$ \\
\hline $23^{8}$ & 28.6 \\
\hline 94 & I I 3 \\
\hline 87 & 10.5 \\
\hline 79 & $9 \cdot 5$ \\
\hline 3 I 2 & 37.5 \\
\hline IOI & $12 \cdot 1$ \\
\hline 234 & $28 \cdot 1$ \\
\hline 65 & $7 \cdot 8$ \\
\hline
\end{tabular}

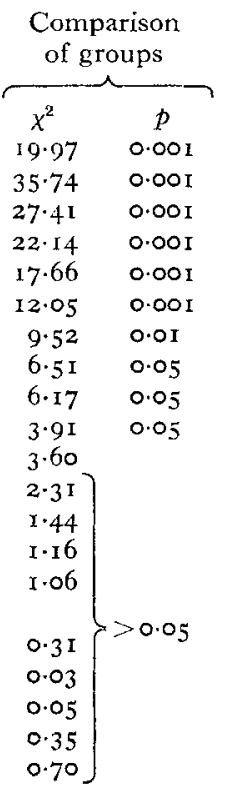


It was found that some of the symptoms earlier believed to be caused by the tapeworm were not related to its presence. For instance there was no difference in the frequency of abdominal symptoms in worm carriers and controls as seen in Table 2. A prominent feature in animals heavily infected with intestinal worms is loss of weight and appetite (for references see Hunter, I953). Contrary to that and to popular belief, human subjects harbouring $D$. latum were found to be hungrier than non-infected subjects, without any signs of loss of weight ('Table 2). This observation indicates that the worm has no direct effect on the calorie metabolism of its host. Objective balance studies are, however, needed to elucidate this point. The common symptom 'craving for salt', not earlier described, is interesting. There is a local term 'hiukominen' for this expression which almost implies salt addiction. This salt hunger appears suddenly and disappears quickly after salt, or salted or raw fish is eaten, and it usually does not occur after the worm has been expelled. The clinical importance of the symptom is uncertain but the possibility of simultaneously occurring electrolyte disturbances exists and requires further investigation. Persons under $3^{\circ}$ years of age had more trouble as a result of their worm infection than older persons. No clear-cut correlation between the symptoms caused by the worm and serum vitamin $B_{12}$ levels could be found.

The predominance of vague general symptoms without special characteristics, shown in Table 2, points to a specific general action on the nutritional state of the host, and seems to rule out severe disturbances other than vitamin $B_{12}$ deficiency. We may assume the existence of some kind of mild intestinal malabsorption. This assumption is supported for instance by the observation made by R. Gräsbeck (personal communication) that patients with tapeworm infection frequently show a low response to an oral vitamin $\mathrm{A}$ absorption test. Further, a mild disturbance in folic acid metabolism occurs in some tapeworm carriers as evidenced by slightly increased urinary excretion of formiminoglutamic acid (Gräsbeck, Björkstén \& Nyberg, I96I). Markkanen, Brummer \& Savola (196I) found a significantly lower urinary excretion of folic acid in anaemic and non-anaemic worm carriers than in a control group. The values for the anaemic group were in turn significantly lower than for the non-anaemic group. Markkanen, Kalliomäki, Oka, Mustakallio \& Brummer ( 1960 ) have also studied the excretion in the urine of thiamine, riboflavin, nicotinic acid, pantothenic acid and biotin. They demonstrated a significantly decreased excretion of thiamine and pantothenic acid in all worm carriers, and a somewhat decreased excretion of riboflavin and biotin. The mean riboflavin content of the blood of worm carriers was found to be $6.4 \mu \mathrm{g} / 100 \mathrm{ml}$ whole blood against $9 \cdot 3 \mu \mathrm{g}$ in the controls (Markkanen, 1962 ). This difference is significant. A decreased urinary excretion and decreased blood content of ascorbic acid has also been reported in both anaemic and non-anaemic fish-tapeworm carriers (Markkanen, Kalliomäki, Oka \& Vanha-Perttula, I960; Villako \& Hange, I958; Villako, I96r).

These observations do not necessarily mean that the worm assimilates and competes with the host organism for all of these substances. More likely, the condition merely reflects a general disturbance in the absorption mechanism. The fact that the values for the above-mentioned nutrients in the majority of both anaemic and 
non-anaemic worm carriers are decreased only to an extent which, though revealed by statistical analysis, is seldom pathologically low, and the fact that there are great individual variations in both groups speaks in favour of this hypothesis. Mechanical factors such as a large bulk of tapeworm present, simultaneous presence of diseases such as heart failure, and dietary factors may in these cases provoke the deficiency state. It is also possible that a change in intestinal flora may be a mediating factor in the production of the postulated disturbance in absorption. Further, we may assume absorption of more or less harmful metabolic products originating from the worm. These ideas are not new, and this subject has been studied many times during the last 70 years in connexion with genuine pernicious anaemia as well as tapeworm anaemia (for references see Birkeland, 1932). Villako (1961) in Estonia has revived this theme. On the basis of the finding of an abnormally high excretion of 'phenolic substances' in subjects with tapeworm anaemia he states that in them a flora consisting predominantly of 'fermentative bacteria' produces the phenols which may have a directly or indirectly harmful effect on the host.

\section{Conclusion}

We can state that: (I) D. latum causes a vitamin $\mathrm{B}_{12}$ deficiency in its human host, (2) mild disturbances in the utilization of some other vitamins of the B group, ascorbic acid, and vitamin $\mathrm{A}$ occur in tapeworm carriers, (3) gross signs of malnutrition are not found in worm carriers, and (4) electrolyte disturbances may exist, but this subject needs further investigation.

\section{REFERENCES}

Birkeland, I. W. (1932). Medicine, Baltimore, Ir, I.

Gräsbeck, R. (1960). Advances in Clinical Chemistry. Vol. 3, p. 299. New York: Academic Press, Inc. Gräsbeck, R., Björkstén, F. \& Nyberg, W. (196I). Nord. Med. 66, 1 343.

Hunter, G. C. (1953). Nutr. Abstr. Rev. 23, 705.

Markkanen, T. (1962). Acta med. scand. r71, r95.

Markkanen, T., Brummer, P. \& Savola, P. (196r). Acta med. scand. 17o, $36 \mathrm{r}$.

Markkanen, T., Kalliomäki, J. L., Oka, M., Mustakallio, E. \& Brummer, P. (1960). Ann. Med. exp. Fenn. 38, 133.

Markkanen, T., Kalliomäki, J. L., Oka, M. \& Vanha-Perttula, T. (rg6o). Ann. Med. intern. Fenn. 49, 263.

Nyberg, W. (1952) Acta med. scand. 144, Suppl. 27 I, p. I.

Nyberg, W. (1958). Acta haemat. 19, 90.

Nyberg, W. (1960a). Acta med. scand. 167, 185 .

Nyberg, W. (1960b). Acta med. scand. 167, I89.

Nyberg, W., Gräsbeck, R. \& Sippola, V. (1958). New Engl.F. Mcd. 253, 2 I6.

Nyberg, W., Gräsbeck, R., Saarni, M. \& von Bonsdorff, B. (196r). Amer. Y. clin. Nutr. 9, 606.

Saarni, M., Nyberg, W., Gräsbeck, R. \& von Bonsdorff, B. (1962). Acta med. scand. (In the Press.)

Villako, K. (1961). Klin. Med., Mosk., no. 8, p. 25.

Villako, K. \& Hange, L. (1958). Vitam. E Horm. 8, 3 I.

von Bonsdorff, B. (1956). Exp. Parasitol. 5, 207.

von Bonsdorff, B. (1958). Proc. int. Congr. trop. Med. vi. Lisbon, 1x, 5.

von Bonsdorff, B. \& Gordin, R. (1952). Acta med. scand. 142, Suppl. 266, p. 283.

von Bonsdorff, B. \& Gordin, R. (1953). Acta med. scand. 144, 263. 